Nat. Hazards Earth Syst. Sci., 18, 1133-1140, 2018

https://doi.org/10.5194/nhess-18-1133-2018

(C) Author(s) 2018. This work is distributed under

the Creative Commons Attribution 4.0 License.

\title{
A new approach for land degradation and desertification assessment using geospatial techniques
}

\author{
Masoud Masoudi ${ }^{1}$, Parviz Jokar ${ }^{2}$, and Biswajeet Pradhan ${ }^{3,4}$ \\ ${ }^{1}$ Department of Natural Resources and Environmental Engineering, Shiraz University, Iran \\ ${ }^{2}$ Department of Natural Resources and Environmental Engineering, Shiraz University, Iran \\ ${ }^{3}$ School of Systems, Management and Leadership, Faculty of Engineering and Information Technology, University of \\ Technology Sydney, Building 11, Level 06, 81 Broadway, Ultimo NSW 2007 (P.O. Box 123), Australia \\ ${ }^{4}$ Department of Energy and Mineral Resources Engineering, Choongmu-gwan, Sejong University, 209 Neungdong-ro \\ Gwangjin-gu, Seoul 05006, Republic of Korea
}

Correspondence: Masoud Masoudi (masoudi@shirazu.ac.ir)

Received: 27 September 2017 - Discussion started: 11 October 2017

Accepted: 25 January 2018 - Published: 10 April 2018

\begin{abstract}
Land degradation reduces the production of biomass and vegetation cover for all forms of land use. The lack of specific data related to degradation is a severe limitation for its monitoring. Assessment of the current state of land degradation or desertification is very difficult because this phenomenon includes several complex processes. For that reason, no common agreement has been achieved among the scientific community for its assessment. This study was carried out as an attempt to develop a new approach for land degradation assessment, based on its current state by modifying of Food and Agriculture Organization (FAO)United Nations Environment Programme (UNEP) index and the normalized difference vegetation index (NDVI) index in Khuzestan province, southwestern Iran. Using the proposed evaluation method it is easy to understand the degree of destruction caused by the pursuit of low costs and in order to save time. Results showed that based on the percent of hazard classes in the current condition of land degradation, the most and least widespread areas of hazard classes are moderate $(38.6 \%)$ and no hazard $(0.65 \%)$ classes, respectively. Results in the desert component of the study area showed that the severe class is much more widespread than the other hazard classes, which could indicate an environmentally dangerous situation. Statistical results indicated that degradation is highest in deserts and rangeland areas compared to dry cultivated areas and forests. Statistical tests also showed that the average degradation amount in the arid region is higher than in other climates. It is hoped that this study's use of geospa-
\end{abstract}

tial techniques will be found to be applicable in other regions of the world and can also contribute to better planning and management of land.

\section{Introduction}

Land degradation is a severe environmental problem confronting the world today (Taddese, 2001). It has detrimental impacts on agricultural productivity and on ecological function that ultimately affect human sustenance and quality of life (Taddese, 2001; Zehtabian and Jafari, 2002; Eliasson et al., 2003; Masoudi, 2010, 2014; Pan and Li, 2013; Barzani and Khairulmaini, 2013; Masoudi and Amiri, 2015). Nearly $25 \%$ of the global biomass has been degraded (Manh Quyet, 2014) because of environmental factors on multiple scales of time and space, comprehending land degradation needs a multi-scale approach (Manh Quyet, 2014; Masoudi, 2014; Masoudi and Amiri, 2015). This approach is important in relation to land management goals. A few studies have investigated land degradation with a multi-scale approach (e.g., Masoudi, 2014; Masoudi and Amiri, 2015; Masoudi and Jokar, 2017).

Land degradation results from different parameters, including climate change and human activity in arid, semi-arid and dry sub-humid regions (UNEP, 1992). Land degradation is still a global issue (UNCED, 1992; UNEP, 2007). In the 1990 s, the main subject of land degradation study was 
about soil degradation assessments. The Global Assessment of Human-induced Soil Degradation (GLASOD) (Oldeman et al., 1991) was the first global evaluation of soil degradation. It is still main global source of soil degradation data (FAO, 2000). The soil degradation map was provided based on the expert judgment of a few hundred scientists in 21 regions of the world (global scale 1:10 million; GLASOD project by Oldeman et al., 1991). Based on mentioned cases, it is not an easy task to evaluate land degradation, and different methods should be investigated (Lal et al., 1997). The information produced by estimating the vulnerability to desertification and erosion (Eswaran and Reich, 1998) gives a different picture than those based on estimating the present (actual) state of land degradation (Oldeman, 1992). For example, the data based on risk assessments show that most regions of the world affected by different severity classes of water and wind erosion are 5-6 times higher than those estimates done on the basis of assessment of present status.

Three aspects of land degradation assessment can be evaluated (FAO-UNEP, 1984): (1) current status, (2) rate or trend, and (3) risk or vulnerability of hazard. Different models have been designed to evaluate these aspects. The FAO-UNEP (1984) introduced a model which evaluates the main parameters affecting desertification processes. The MEDALUS ${ }^{1}$ model showed regions that are environmentally sensitive areas (ESA) in relation to desertification (Kosmas et al., 1999). In this method, four main quality layers including soil, climate, vegetation and management are evaluated. Some other important models are GLASOD (Oldeman et al., 1991), ASSOD ${ }^{2}$ (Van Lynden and Oldeman, 1997) and recently $\mathrm{LADA}^{3}$ (FAO, 2002; Ponce Hernandez and Koohafkan, 2004). LADA has been set up by FAO, UNEP-GEF and various other partners to assess land degradation in dryland areas.

Geographic Information Systems (GIS) in conjunction with remote sensing (RS) and photogrammetry are also suitable instruments in order to estimate environmental hazards. The GIS is used to analyze satellite images, aerial photos and field survey data. It is also used to determine new hazards through the overlaying of hazard data sets. Studies have also shown that GIS and RS can investigate temporal variations in desertification and land degradation, analyze changes between land cover features, develop base-line desertification maps, and also monitor desertification (Congalton, 1996; Lu et al., 2004; Rangzan et al., 2008; Higginbottom and Symeonakis, 2014; Miehe et al., 2010; Pinzon and Tucker, 2014). In these studies, RS uses satellite images or aerial photos to produce trend maps showing changes in land condition through time it always includes linkages with ground observations.

\footnotetext{
${ }^{1}$ Mediterranean Desertification and Land Use

${ }^{2}$ Assessment of the Status of Human-induced Soil Degradation in South and Southeast Asia

${ }^{3}$ Land Degradation Assessment in Drylands
}

Vegetation-based models have also been applied in global, continental, and national evaluations of land degradation (Eklundh and Olsson, 2003; Julien et al., 2006; Duanyang et al., 2009; Pinzon and Tucker, 2014; Seboka, 2016). Researchers often apply the $\mathrm{NDVI}^{4}$ index as a remotely sensed signal to analyze changes in vegetation. Vlek et al. (2008, 2010) investigated long-term NDVI trends in relation to the inter-annual dynamics of rainfall and atmospheric fertilization, in order to determine the extent to which humans affect the NPP (net primary productivity). Lanorte et al. (2014) used NDVI time series to monitor vegetation recovery after disturbances by fire at two test sites in Spain and Greece. Remote sensing is also being used in vulnerability analysis (Oldeman et al., 1991; Van Lynden and Oldeman, 1997; Sepehr et al., 2007; Bai et al., 2008; Masoudi and Zakeri Nejad, 2010; Hein et al., 2011; D’Odorico et al., 2013; Masoudi, 2014; Masoudi and Amiri, 2015), focusing on spatialized models for assessment of desertification or land degradation. One can retrieve information on various spatial and temporal scales and in addition, models can be modified and then re-calibrated with update data on the actual status of the environment (De Jong, 1994; Boer, 1999).

Among the three aspects of degradation, more emphasis is placed at present on the current status of degradation. This issue is also observed in some important desertification models like FAO-UNEP (1984), GLASSOD (Oldeman et al., 1991) and ASSOD (Van Lynden and Oldeman, 1997). Therefore the main aim of this paper is to develop a new technique in order to evaluate the current state of land degradation in southwestern Iran using satellite images and GIS.

\section{Material and methods}

\subsection{Study area}

Khuzestan province (Fig. 1) is located in southwestern Iran, with an area of $63633 \mathrm{~km}^{2}$. This province is located between the latitude of $29^{\circ} 59^{\prime}$ and $33^{\circ} 01^{\prime} \mathrm{N}$ and the longitude of $46^{\circ} 48^{\prime}$ and $50^{\circ} 30^{\prime} \mathrm{E}$. The estimated population in the study area is 4710509 (Population and housing statistics of Khuzestan, 2016). Ahvaz is the capital city of Khuzestan province. The climate of the study area varies from arid to humid. The northern parts of the province experience cold weather, whereas the southern parts experience tropical weather (Zarasvandi et al., 2011). Most parts of the province are arid and average of precipitation is $266 \mathrm{~mm}_{\text {year }}{ }^{-1}$, but mean annual rainfall reaches $950 \mathrm{~mm}$ in the northeast (Masoudi and Elhaeesahar, 2016). The main period of precipitation is during the winter. Temperature in most parts reaches above $50^{\circ} \mathrm{C}$ during summer. Topographic elevations in the province vary between 0 and $3740 \mathrm{~m}$. Geomorphologically, Khuzestan province is located in a basin occupied by Cenozoic-Quaternary alluvial sediment mostly derived from

\footnotetext{
${ }^{4}$ Normalized Difference Vegetation Index
} 


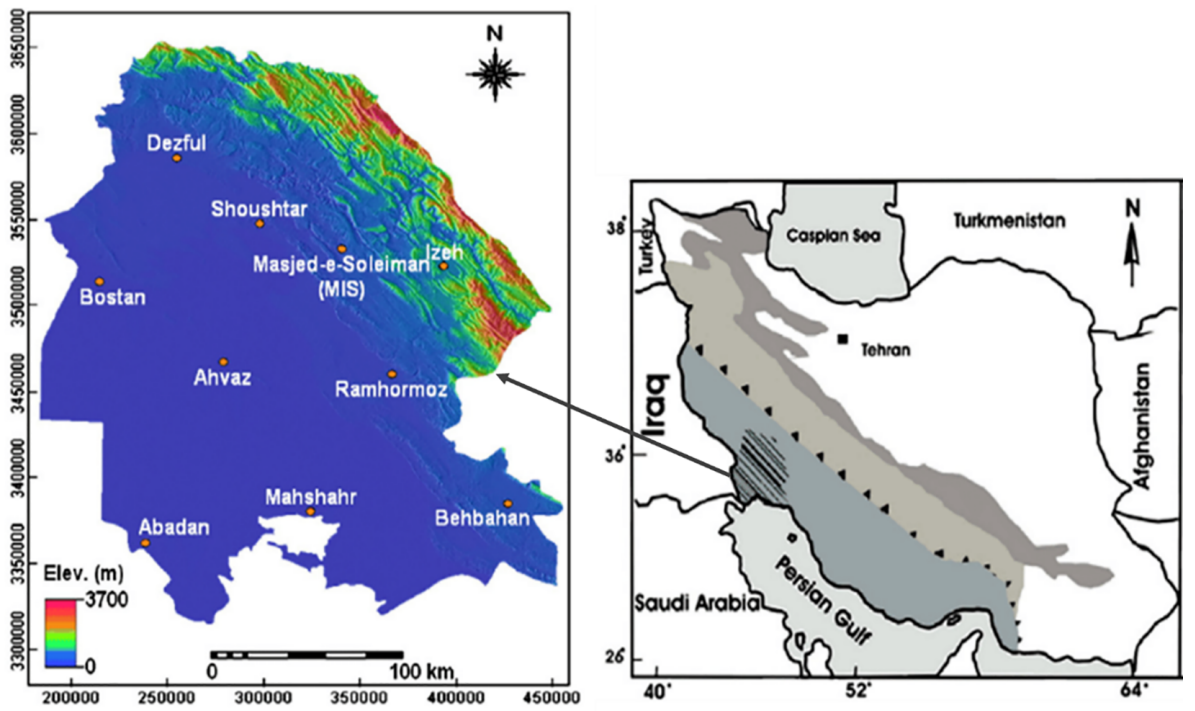

Figure 1. Location of the study area in Iran.

the chemical and mechanical erosion of the Zagros Mountains (Zarasvandi et al., 2011).

\subsection{Data and methodology}

The difference between actual or current production (in physical or monetary terms) and the maximum attainable (potential) production is often used in a suitability assessment for a crop (FAO-UNEP, 1984). On the other hand, this indicator may be used to assess the state of land deterioration in terms of plant loss. Compared to the other methods of assessment of the current state of degradation, this indicator seems to be more significant, as plant loss is affected not only by erosion, but also by land deterioration and all environmental influences, for that matter. To show the current state of land degradation, this indicator has been used by several models including the FAO-UNEP model of desertification (FAO-UNEP, 1984), LADA (FAO, 2002; Ponce Hernandez and Koohafkan, 2004) and the models of GLASSOD (Oldeman et al., 1991) and ASSOD (Van Lynden and Oldeman, 1997). Evaluation of the present status of land degradation in the FAO-UNEP model and the models of GLASSOD and ASSOD is emphasized in Eq. (1):

degradation $=\frac{\text { current production }}{\text { potential production }}$.

Evaluation of the current production by field sampling of vegetation cover is not suitable for regional scale. Conversely, potential production is calculated by ecological conditions such as average rainfall and soil limitations by general models that are inaccurate on a regional scale (FAO-UNEP, 1984). For both of them a lot of data are required to assess degradation in regional studies and this can make assessment difficult in some regions (Oldeman et al., 1991; Van Lynden and Oldeman, 1997).

Based on the GLADA ${ }^{5}$ approach, current productivity in regional studies and larger areas can be estimated by general equations using an NDVI indicator, but there is concern about their overall application for regional studies. Therefore, this proposed theory helps us find potential production while taking into consideration the non-degraded situation for each land use in each individual area.

Because of the above problems in this study instead of estimating potential production and current production we use only the values of the NDVI. The NDVI is calculated with Eq. (2):

$\mathrm{NDVI}=\frac{\mathrm{NIR}-\mathrm{red}}{\mathrm{NIR}+\text { red }}$,

where NIR is the near-infrared band and red is the red band. This study uses NDVI data (from MODIS satellite images) produced by the modeling and mapping images at $500 \mathrm{~m} \mathrm{spa-}$ tial resolution. Vegetation images were extracted from the USGS site relating to the years of 2011 and 2013, chosen as there was normal rainfall during these years. Then the geometric position was corrected via georeference.

In the current work, three images from March, April and May represent the highest production of natural resources in every year measured in the study area. Then one image was extracted through selecting the image with the highest NDVI among them for each pixel in ENVI 4.7 software wherein maximum NDVI represents the highest production in the mentioned 3 months and thus whole year for each point of study area.

In order to reduce fluctuations between 2011 and 2013 (from drought, pests, etc.) an average from images of two

\footnotetext{
${ }^{5}$ Global Land Degradation Assessment
} 
Table 1. FAO-UNEP classification for the current state of degradation (based on percent of current production to potential production).

\begin{tabular}{lrrrrr}
\hline Degree of degradation & None & Slight & Moderate & Severe & Very severe \\
\hline Percent of current production to potential production & $>100$ & $80-100$ & $40-80$ & $20-40$ & $<20$ \\
\hline
\end{tabular}

years including the maximum NDVI for each pixel was obtained to show an average of the highest production for each point using Eq. (3):

$$
\begin{aligned}
& \text { average of NDVI } \max = \\
& \frac{\text { NDVI } \max _{\text {in } 2011}+\text { NDVI }_{\max } \text { in } 2013}{2} .
\end{aligned}
$$

The average of maximum NDVI is an indicator of the current production in the study area. In order to find the potential for production based on production in a non-degraded situation, the study area was divided to several land units. Land units are prepared according to the overlaying of three maps of precipitation, land use and land form (divided into plains and highlands). Land units were coded in two steps by Eq. (4) (Makhdoum, 2001):

$E=J \times(I-1)+J_{i}$,

where $E$ is the unit code, $J$ is the number of classes for underlying map, $I$ is the code of class for the overlying map and $J_{i}$ is the code of class for underlying map.

In the next step standard deviation (SD), average and maximum amount of NDVI values for each land unit were calculated to help us find the potential of NDVI for each land unit, as an indicator to show the potential for production in the study area. To find the potential for production in each land unit in a region we can consider the production in a region with no or very minor anthropogenic activity for the same class of land unit. However, finding the conservational condition of all land units on regional or higher scales can be very difficult. Therefore this technique is helpful for finding the potential for production in each land unit or minor ecosystem in a region. Equation (5) is used for this case:

potential NDVI in each land unit $=$

$$
((\text { average }+\mathrm{SD})+\max ) / 2 \text {. }
$$

This amount shows a high value in the NDVI in each land unit as an indicator of higher production in non-degraded situations. Therefore, the current state of land degradation was calculated for each pixel using Eq. (6) that is equal to the index of FAO-UNEP:

$$
\begin{aligned}
\text { current state of degradation } & =\frac{\text { current production }}{\text { potential production }} \\
& \approx \frac{\mathrm{NDVI}_{\max }}{\mathrm{NDVI}_{\text {potential }}},
\end{aligned}
$$

thus the current state of land degradation is classified based on the FAO-UNEP classification (Table 1).
In order to evaluate the accuracy of the proposed model quantitatively, the prepared map was compared to the real situation on the ground. This ground reality map was prepared based on the highest hazard class of current degradation among water and wind erosion, soil salinity and vegetation cover. Therefore information was used from 402 points stratified randomly in the Ghareh Aghaj basin, southern Iran.

\section{Results and discussion}

Most studies conducted by the likes of Feiznia et al. (2001) and on a global scale such as Universal Soil Loss Equation (USLE) for water erosion or Metternicht and Zinck (1997) for soil salinity have done so based on the calculation of present status of degradation.

The different types of degradation maps such as those that cover soil salinization or wind erosion based solely on the present status of said degradation make it difficult to evaluate whether regions are at risk of land degradation or desertification. It requires knowledge of the level of the effects of all degradation types on the region and thus makes assessment difficult. This kind of classification allows a new technique using potential of production, taking into consideration the regional condition. Instead of using different models that are not universally applicable. This can be seen as the first effort towards identifying regions under each severity class of degradation.

The main types of land degradation in the province studied are water and wind erosion, soil salinization, lowering of ground water table and vegetation degradation. The hazard map of the province is one example of this kind of methodology for assessing the current state of land degradation (Fig. 2). Figures 2 and 3 show that about $30 \%$ of the land in the province is in a severe or very severe state of land degradation. Such areas are observed much more on plains in comparison to the highlands. The main types of land degradation in the plains are soil salinity and wind erosion. While in the highlands, moderate degradation is more common with the occurrence of water erosion in steep lands. Among the severity classes, regions under moderate hazard cover the greatest area $(38.6 \%$ of the study area) while regions under no hazard cover the least ( $0.65 \%$ of the study area).

Results of the test between the two maps of the current model and maps prepared by taking into consideration ground reality of degradation show a significant relationship at the 0.01 level $(R=0.264)$. This result indicates the current 
Table 2. Tables of analysis of the variance between degradation severity and different ecosystem types.

\begin{tabular}{lrrrrr}
\hline & Sum of squares & df & Mean square & $F$ & Sig. \\
\hline Between groups & 109.729 & 3 & 36.576 & $85.126^{* *}$ & 0.000 \\
Within groups & 745.482 & 1735 & 0.430 & & \\
\hline Total & 855.211 & 1738 & & & \\
\hline
\end{tabular}

** Significant at level 0.01 .

Table 3. Tables of analysis of the variance between degradation severity and different climate types.

\begin{tabular}{lrrrrr}
\hline & Sum of squares & df & Mean square & $F$ & Sig. \\
\hline Between groups & 205.373 & 5 & 41.075 & $99.657^{* *}$ & 0.000 \\
Within groups & 744.770 & 1807 & 0.412 & & \\
Total & 950.142 & 1812 & & & \\
\hline
\end{tabular}

** Significant at level 0.01
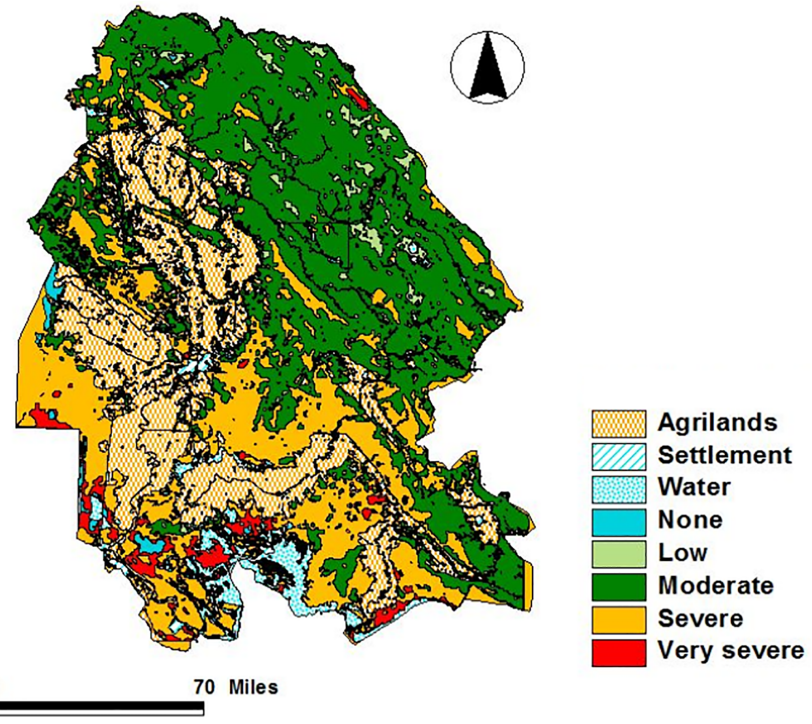

Figure 2. Map of the current state of land degradation in the study area.

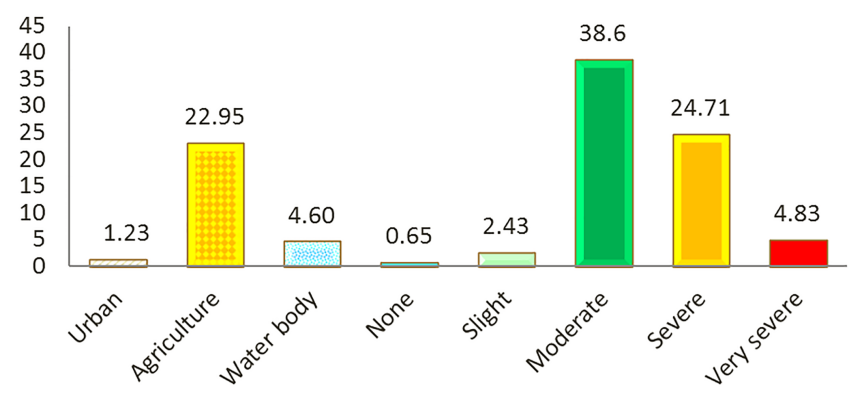

Figure 3. Percent of the land which is classified under each severity class of land degradation in the study area.

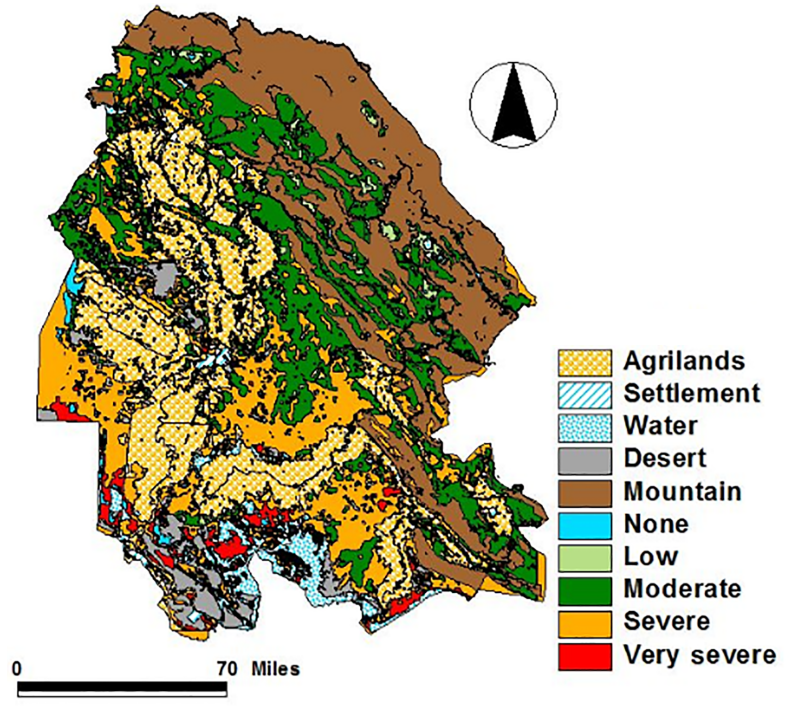

Figure 4. Map of the current state of desertification in the study area.

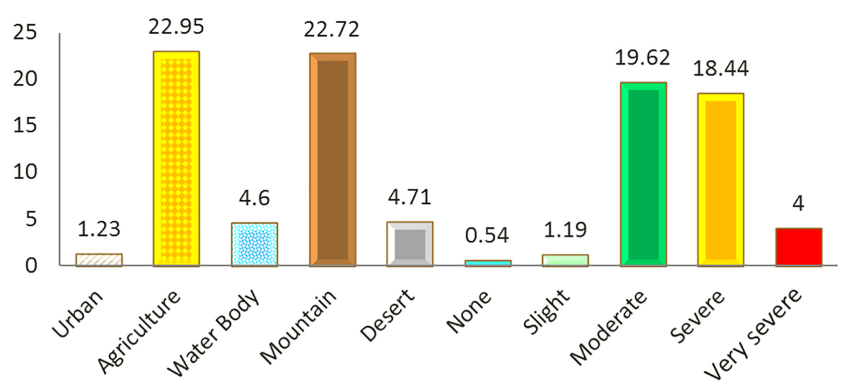

Figure 5. Percent of the land which is classified under each severity class of desertification in the study area. 


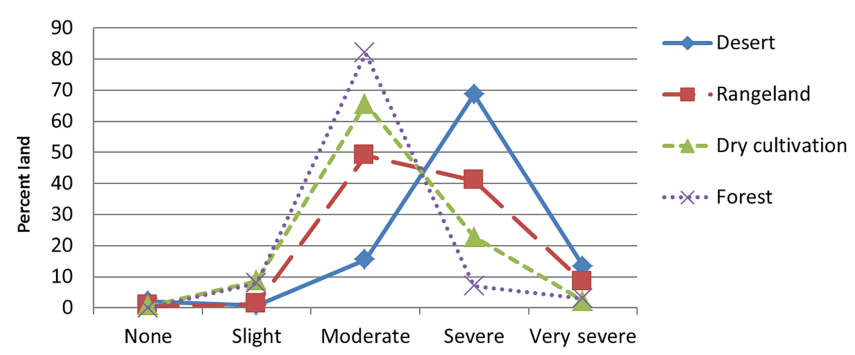

Figure 6. Percent of the area classified under each severity class of degradation for each form of land use.

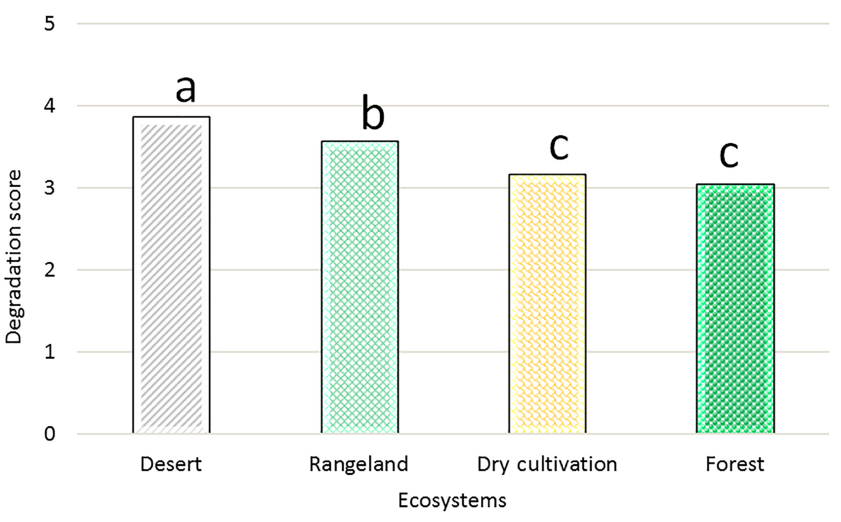

Figure 7. Average of degradation amount in the different ecosystem types using the Duncan test: $\mathrm{a}, \mathrm{b}$ and $\mathrm{c}$ show difference among class means at a significant level of 0.01 .

method is useful for finding the degree of land degradation or desertification.

To qualify the severity classes of the desertification map, first desert land was determined based on new definition derived from the UN definition of desertification (UNEP, 1992). There is controversy between experts of the natural resource offices in Iran about the separation of desert land from poor rangeland. Based on their new recommendation and the desertification definition by UN, in this assessment "desert" is defined as "plains that satisfy two conditions, a climate of arid, semi-arid or dry sub-humid, and vegetation cover of less $5 \%$ ". Therefore, mountainous areas and regions with other climates are not subject to desertification but instead to land degradation.

A comparison between the map of land degradation and different land uses in the study area including forest, rangeland, dry cultivation and desert areas (e.g., barren land, saline land and sand dunes) shows that a greater proportion of desert lands are under a severe state of degradation, while for other mentioned land uses the most widespread class is of moderate hazard (Fig. 6). The table of analysis of variance (Table 2) shows that there is a highly significant relationship between the severity of land degradation and each ecosystem types of the 1738 points stratified randomly in the study area. The Duncan test shows that the average amount

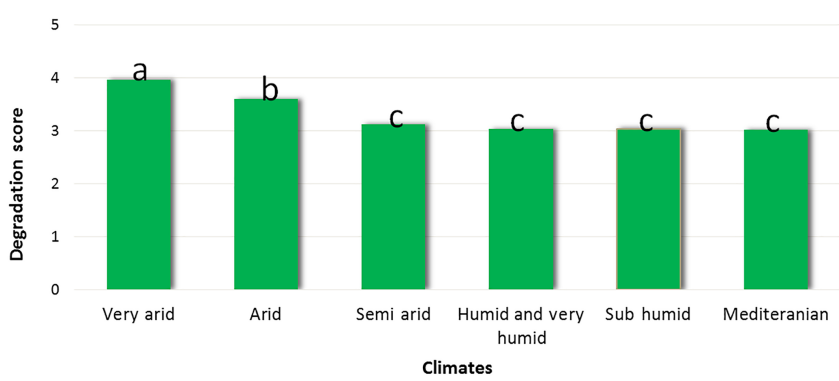

Figure 8. Average of degradation amount in the different climate types using the Duncan test: $\mathrm{a}, \mathrm{b}$ and $\mathrm{c}$ show difference among class means at a significant level of 0.01 .

of degradation in the desert area is significantly higher than other ecosystems while forest areas show the least degradation (Fig. 7). Results of this statistical test confirm the results of the percent of land under each severity class in Fig. 6. This result implies the obvious - that severe degradation is occurring in the desert areas of study. However, in some reports such as the ASSOD assessment of Asian countries (FAO, 1994), it is mentioned that in desert areas degradation is low and a stable condition is observed. This severe degradation may be related to different causes of degradation that are affecting the region, and it is concluded that the deserts are younger than other deserts such as the Lut desert in Iran.

The table of analysis of variance (Table 3 ) shows that there is a highly significant relationship in the study area between the severity of degradation at 1812 points stratified randomly and different climate types of said areas. The Duncan test shows that the average degradation amount in the arid region is higher than in other climates (Fig. 8). These results confirm those results derived from other studies that mentioned higher degradation in arid zones compared to humid zones in Iran and other Asian countries (FAO, 1994; Masoudi et al., 2006, 2007; Masoudi, 2014; Masoudi and Amiri, 2015; Masoudi and Jokar, 2017). In the case of Figs. 7 and 8 some research (FAO, 1994; Van Lynden and Oldeman, 1997; Salehi, 2017) has shown that land degradation in regions with arid climates is higher than in humid areas. Also Salehi (2017) showed that land degradation in desert and rangeland ecosystems is higher than in forest and rain-fed ecosystems.

\section{Conclusions}

The desertification map (Fig. 4) is the same as the land degradation map but with the difference that desert lands and mountainous areas are defined on the former. Once again from this map the areas under each severity class were identified. From Figs. 4 and 5, it is concluded that in Khuzestan, regions under both the severe and very severe (22.4\%) classes are more widespread compared to regions under other severity classes, showing an environmentally dangerous situation in terms of desertification. Results of the test between 
two maps prepared by the current model and ground reality of degradation confirms that this new approach, based on using FAO-UNEP view and NDVI index, is a good technique for assessing the current state of land degradation. Results show that degradation is the highest in the desert followed by rangelands, dry, cultivated lands and forests. Results of current study show that degradation is higher in arid regions compared to other climate types, confirming many research results in this field. Also, such areas will need immediate attention for remedial measures of reclamation and conservation for each type of degradation such as those measures mentioned by Masoudi (2014), Masoudi and Amiri (2015), and Masoudi and Jokar (2017).

Data availability. Data sets used in this article are available from the corresponding author upon request due to the high volume of satellite images and GIS layers.

Competing interests. The authors declare that they have no conflict of interest.

Acknowledgements. The authors express their sincere thanks to all involved governmental departments and individuals for their active co-operation, thoughtful advice, constructive criticism and efficient guidance. As well as for preparing the information, maps and reports required for carrying out this project's work.

Edited by: Rosa Lasaponara

Reviewed by: Two anonymous referees.

\section{References}

Bai, Z. G., Dent, D. L., Olsson, L., and Schaepman, M. E.: Global assessment of land degradation and improvement 1. Identification by remote sensing, ISRIC - World Soil Information, Food and Agriculture Organization of the United Nations, 2008.

Barzani, M. and Khairulmaini, O. S.: Desertification risk mapping of the Zayandeh Rood Basin in Iran, J. Earth Syst. Sci., 122, 1269-1282, https://doi.org/10.1007/s12040-013-0348-1, 2013.

Boer, M. M.: Assessment of Dryland Degradation: Linkage Theory and Practice Through Site Water Balance Modeling, Netherlands geographical studies, 251, Utrecht, 1999.

Congalton, R. G.: Accuracy assessment: a critical component of land cover mapping, in: Gap Analysis: A Landscape Approach to Biodiversity Planning, edited by: Scott, J. M., Tear, T. H. and Davis, F., Bethesda, Maryland, American Society for Photogrammetry and Remote Sensing, 119-131, 1996.

De Jong, S. M.: Applications of Reflective Remote Sensing for Land Degradation Studies in a Mediterranean Environment, Netherlands geographical studies, 177, Utrecht, 1994.

D'Odorico, P., Bhattachan, A., Davis, K. F., Ravi, S., and Runyan, C. W.: Global desertification: drivers and feedbacks, Adv. Water Resour., 51, 326-344, 2013.
Duanyang, X., Xiangwu, K., Dongsheng, Q., Dafang, Z., and Jianjun, P.: Quantitative assessment of desertification using landsat data on a regional scale - a case study in the Ordos Plateau, China, Sensors, 9, 1738-1753, https://doi.org/10.3390/s90301738, 2009.

Eklundh, L. and Olsson, L.: Vegetation index trends for the African Sahel 1982-1999, Geophys. Res. Lett., 30, 1430-1433, https://doi.org/10.1029/2002GL016772, 2003.

Eliasson, A., Rinaldi, F. M., and Linde, N.: Multicriteria decision aid in supporting decisions related to groundwater protection, Environ. Manag., 32, 589-601, https://doi.org/10.1007/s00267003-2906-9, 2003.

Eswaran, H. and Reich, P. F.: Desertification: a global assessment and risk to sustainability, in: Proceedings of the 16th International Congress of Soil Science, Montpellier, France, 1998.

FAO: Land degradation in South Asia: its Severity Causes and Effects Upon the People, FAO, UNDP and UNEP report, Rome, 1994.

FAO: Land Resource Potential and Constraints at Regional and Country Levels, World Soil Resources Reports 90, FAO, Land and Water Development Division, Rome, 114 p., 2000.

FAO: Land Degradation Assessment in Drylands: LADA, FAO, Rome, 2002

FAO-UNEP: Provisional Methodology for Assessment and Mapping of Desertification, FAO, Rome, 84 p., 1984.

Feiznia, S., Gooya, A. N., Ahmadi. H., and Azarnivand, H.: Investigation on desertification factors in Hossein-Abad Mish Mast plain and a proposal for a regional model, Journal of Biaban, 6 , 1-14, 2001.

Hein, L., de Ridder, N., Hiernaux, P., Leemans, R., de Wit, A., and Schaepman, M.: Desertification in the Sahel: towards better accounting for ecosystem dynamics in the interpretation of remote sensing images, J. Arid Environ., 75, 1164-1172, https://doi.org/10.1016/j.jaridenv.2011.05.002, 2011.

Higginbottom, T. P. and Symeonakis, E.: Assessing land degradation and desertification using vegetation index data: current frameworks and future directions, Remote Sens.-Basel, 6, 9552 9575, https://doi.org/10.3390/rs6109552, 2014.

Julien, Y., Sobrino, J. A., and Verhoef, W.: Changes in land surface temperatures and NDVI values over Europe between 1982 and 1999, Remote Sens. Envrion., 103, 43-55, https://doi.org/10.1016/j.rse.2006.03.011, 2006.

Kosmas, C., Poesen, J., and Briassouli, H.: Key Indicators of Desertification at the Environmentally Sensitive Areas (ESA) Scale, The Medalus Project: Mediterranean Desertification and Land Use, Manual on Key Indicators of Desertification and Mapping Environmentally Sensitive Areas to Desertification, Project report, European Commission, 1999.

Lal, R., Winfried, E. H., Valentin, C., and Stewart, B.: Methods for Assessment of Land Degradation, CRC, Boca Ration, 1997.

Lanorte, A., Lasaponara, R., Lovallo, M., and Telesca, L.: FisherShannon information plane analysis of SPOT/VEGETATION Normalized Difference Vegetation Index (NDVI) time series to characterize vegetation recovery after fire disturbance, Int. J. Appl. Earth Obs., 26, 441-446, https://doi.org/10.1016/j.jag.2013.05.008, 2014.

Lu, D., Mausel, P., Brondizios, E., and Moran, E.: Change detection techniques, Int. J. Remote Sens., 25, 2365-2407, https://doi.org/10.1080/0143116031000139863, 2004. 
Makhdoum, M.: Fundamental of Land Use Planning, Tehran University Press, 289 p., 2001.

Manh Quyet, V.: Multi-Level Assessment of Land Degregation, The Case of Vietnam, PhD Thesis, ETH Zurich Research Collection, 128 p., 2014.

Masoudi, M.: Risk Assessment and Remedial Measures of Land Degradation, in Parts of Southern Iran, Lambert Academic Publishing (LAP), Germany, 220 p., ISBN: 978-3-8383-7718-6, 2010.

Masoudi, M.: Risk assessment of vegetation degradation using GIS, J. Agr. Sci. Tech.-Iran, 16, 1711-1722, 2014.

Masoudi, M. and Amiri, E.: A new model for hazard evaluation of vegetation degradation using DPSIR framework, a case study: Sadra region, Iran, Pol. J. Ecol., 63, 1-9, https://doi.org/10.3161/15052249PJE2015.63.1.001, 2015.

Masoudi, M. and Elhaeesahar, M.: Trend assessment of climate changes in Khuzestan Province, Iran, Natural Environment Change, 2, 143-152, 2016.

Masoudi, M. and Jokar, P.: A new model for desertification assessment using Geographic Information System (GIS) a case study, Runiz Basin, Iran, Pol. J. Ecol., 65, 236-246, https://doi.org/10.3161/15052249PJE2017.65.2.006, 2017.

Masoudi, M. and Zakeri Nejad, R.: Hazard assessment of desertification using MEDALUS model in Mazayjan plain, Fars province, Iran, Eco. Env. Cons., 16, 425-430, 2010.

Masoudi, M., Patwardhan, A. M., and Gore, S. D.: Risk assessment of water erosion for the Qareh Aghaj Sub Basin, southern Iran, Stoch. Env. Res. Risk A., 21, 15-24, https://doi.org/10.1007/s00477-006-0040-y, 2006.

Masoudi, M., Patwardhan, A. M., and Gore, S. D.: Risk assessment of lowering of ground water table using GIS for the Qareh Aghaj Sub Basin, southern Iran, J. Geol. Soc. India, 70, 861-872. 2007.

Metternicht, G. and Zinck, J. A.: Spatial discrimination of salt and sodium-affected soil surfaces, Int. J. Remote Sens., 18, 25712586, https://doi.org/10.1080/014311697217486, 1997.

Miehe, S., Kluge, J., von Wehrden, H., and Retzer, V.: Longterm degradation of Sahelian rangeland detected by 27 years of field study in Senegal, J. Appl. Ecol., 47, 692-700, https://doi.org/10.1111/j.1365-2664.2010.01815.x, 2010.

Oldeman, L. R.: The Global Extent of Soil Degradation, ISRIC BiAnnual Report, 19-36, 1992

Oldeman, L. R., Hakkeling, R. T. A., and Sombroek, W. G.: World Map of the Status of Human-Induced Soil Degradation: an Explanatory Note, International Soil Reference and Information Centre, Wageningen, UNEP, Nairobi, 27 p. +3 maps, revised edition, 1991.

Pan, J.-H. and Li, T.-Y.: Extracting desertification from LANDSAT imagery based on spectral mixture analysis and AlbedoVegetation feature space, Nat. Hazards, 25, 915-927, https://doi.org/10.1007/s11069-013-0665-3, 2013.

Pinzon, J. E. and Tucker, C. J.: A non-stationary 1981-2012 AVHRR NDVI3g time series, Remote Sens.-Basel, 6, 69296960, https://doi.org/10.3390/rs6086929, 2014.
Ponce Hernandez, R. and Koohafkan, P.: Methodological framework for Land Degradation Assessment in Drylands (LADA), FAO report, Rome, 2004.

Population and housing statistics of Khouzestan: available at: http: //www.asrejonoob.ir/khuzestan, last access: 20 August 2016.

Rangzan, K., Sulaimani, B., Sarsangi, A. R., and Abshirini, A.: Change detection, mineralogy, desertification mapping in east and northeast of Ahvaz City, SW Iran using combination of remote sensing methods, GIS and ESAs model, Global Journal of Environmental Research, 2, 42-52, 2008.

Salehi, M.: Evaluation and modeling of the current status of land degradation in Fars province using remote sensing and geographic information system, M.Sc. thesis, Faculty of Agriculture, Shiraz University, Shiraz, Iran, 2017.

Seboka, G. N.: Spatial assessment of NDVI as an indicator of desertification in Ethiopia using remote sensing and GIS, M.Sc. thesis, Department of Physical Geography and Ecosystem Science, Lund University, 2016.

Sepehr, A., Hassanli, A. M., Ekhtesasi, M. R., and Jamali, J. B.: Quantitative assessment of desertification in south of Iran using MEDALUS method, Environ. Monit. Assess., 134, 243-254, https://doi.org/10.1007/s10661-007-9613-6, 2007.

Taddese, Y.: Land degradation: a challenge to Ethiopia, Environ. Manage., 27, 815-824, https://doi.org/10.1007/s002670010190, 2001.

UNCED: Managing Fragile Ecosystems: Combating Desertification and Drought, Agenda 21, Chapter 12, United Nations Conference on Environment and Development, 21, 1992.

UNEP (United Nations Environmental Program): World Atlas of Desertification, editorial commentary by: Middleton, N. and Thomas, D. S. G., Arnold, London, 1992.

UNEP: Global Environmental Outlook GEO-4, UN Environment Programme, Nairobi, 2007.

Van Lynden, G. W. J. and Oldeman, L. R.: Assessment of the Status of Human-Induced Soil Degradation in South and Southeast Asia (ASSOD), International Soil Reference and Information Centre, 1997.

Vlek, P. L. G., Le, Q. B., and Tamene, L.: Land Decline in LandRich Africa: a Creeping Disaster in the Making, CGIAR Science Council Secretariat, Rome, Italy, 2008.

Vlek, P. L. G., Le, Q. B., and Tamene, L.: Assessment of land degradation, its possible causes and threat to food security in subSaharan Africa, in: Food Security and Soil Quality, edited by: Lal, R., and Stewart, B. A., Taylor and Francis, 430, 2010.

Zarasvandi, A., Carranza, E. J. M., Moore, F., and Rastmanesh, F.: Spatio-temporal occurrences and mineralogicalgeochemical characteristics of airborne dusts in Khuzestan province (southwestern Iran), J. Geochem. Explor., 111, 138151, https://doi.org/10.1016/j.gexplo.2011.04.004, 2011.

Zehtabian, G. and Jafari, R.: Evaluation of water resources degradation in Kashan area using desertification model, Journal of Environmental Studies, 28, 19-30, 2002. 